\title{
Global Travel Restriction's Effect on The Number of Deaths from COVID - 19: An Analysis on Global COVID-19 Data Md Fourkan*1
}

\section{*Author Biography}

Md Fourkan is a PhD student in the department of marketing and entrepreneurship at Kent State University. He got his master's in economics from South Dakota State University. His research concentrates on health economics, public policy, and firm performance.

\begin{abstract}
Modeling global travel restrictions and number of cases and deaths from COVID-19 we have shown that effective regulatory actions such as global travel restrictions could reduce the number of deaths per million from this pandemic. We have controlled for country specific demographic and geographic variables such as average temperature, number of populations, alcohol intake per day, test in per million to find out the ceteris paribus effect of global travel restrictions on the number of deaths from COVID-19 in countries around the world. By classifying countries across three layers of global travel restrictions status, based on their regulatory actions, against COVID19 our model reveals that global travel restriction could have saved many lives. The findings from this paper can be considered in future for any further spike of COVID-19 along with any other pandemic in future.
\end{abstract}

Keywords: travel restrictions, COVID-19, loss of lives, economy, imported case

\section{Introduction}

The first global case of novel COVID-19 virus (2019-nCoV) was reported on 13 January 2020 in Thailand confirmed by authority there to be imported from Wuhan, Hubei Province, China (Organization, 2020b). Though the first reported case of COVID-19 was from Wuhan City, Hubei Province of China on 31 December 2019 (Organization, 2020b). World Health Organization declared COVID-19 a public health emergency of universal concern on January 30, 2020 (Organization, 2020a). That the story started from here, hitherto, it is disrupting and knocking the lives of people from around the world, and it seems like the scars will continue for many years to come.

There is no doubt coronavirus pandemic has upended the whole world not only by killing millions of people till today but also by staggering world economies severely. Consequently, the world bank calculates that the world economy possibly shrank by $4.3 \%$ in 2020 , a holdup comparable to depression and the two world wars (Bank, 2021). Existing gap in the health system resilience and public health response in time of emergencies across countries has been exasperated and revealed

\section{${ }^{1}$ Correspondence}


by the pandemic (Wang, Duan, Jin, \& Zheng, 2020). The fear and toll of COVID-19 on social, psychological, and physical lives of people around the world is also terrible (Sharma et al., 2020). The U.S has been cornerstone of the hit as it stands on top of both the number of covid-19 cases and deaths across countries in the world (Health, 2021).

Since the first case in the world on 13 January 2020, severe acute respiratory syndrome COVID19 (SARS-CoV-2) has spread to every cities and countries and has resulted in more than 105.74 million cases and 2.308 million deaths as of 02 February 2021 (University, 2021). The death rate from COVID-19, the third of the severe acute respiratory syndrome (SARS) family, shows (1$3 \%$ ) which is lower than the other two varieties of the same family, MERS outbreak (mortality rate of 35-40\%) and SARS outbreak (mortality rate of 9-10\%). Nevertheless, if we take into account the number of deaths from COVID-19 it is overwhelmingly more dire and appalling virus in the 21st century so far (Sahu, Mishra, \& Lal, 2020).

This pandemic has placed its scars on the people's lives, livelihoods, and healthcare so much so that it might take several years to recover the damage. The approval of a few number of vaccines by different countries are making us hopeful about an end to the pandemic but it is still a matter of several years to make the herd immunity, i.e., to get 75 percent of the world population vaccinated (The bloomberg, 2021).

COVID, Reiner, Barber, and Collins (2020) used the number of COVID-19 cases and deaths data from 1 February 2020 to 21 September 2020 from the United States at the state level to model possible trajectories of the virus infections and the effects of non-pharmaceutical interventions such as social distancing mandates and levels of mask use. They projected that around five hundred thousand lives could be lost to COVID-19 across the United States by 28 February 2021. They forecast that implementing universal mask use i.e., 95\% mask use in public could save an additional 129,574 (85,284-170,867) lives from September 22, 2020, through the end of February 2021. Although Thompson (2020) speculated in their paper, published around January 2020, that the transmission can be checked by taking surveillance efforts nonetheless we have seen, as of February 2nd 2021, it went out of control and costs around 2.5 million lives around the world.

Therefore, it needs more research from more diverse aspects and at the most feasible level possible to explore what have facilitated this virus to come this far and take millions of lives. Surprisingly, no paper that we studied from literature, as of February 2nd, 2021, on COVID-19 has performed a model using data representative of the whole world on the number of deaths caused by various levels of global travel restrictions undertaken by countries. Finally, our focus in this paper is to make contribution in this area by discussing various aspects and analyzing data on global travel restrictions and its impact on number of deaths from COVID-19.

\section{Travel Restriction's Impact on Covid-19 Cases and Deaths}

In January, 2020, Wu, Leung, and Leung (2020) forecasted exponential outbreak of the virus in many other cities in China such as Chongqing, Beijing, Shanghai, Guangzhou, and Shenzhen since three was already a lag of 1-2 weeks of Wuhan outbreak without lockdown implementation. They cautioned it would not take long time for the virus to spread in other cities around the world and encouraged to take preparedness plans and mitigation interventions globally. According to the U.S Center for Disease Control and Preventions' (CDC) website travel facilitates the chance of 
spreading and catching COVID-19. Therefore, CDC continues to recommend people to postpone travel and stay home (Prevention, 2021).

In this type of contagious virus such as SARS-CoV-2, it can spread very quickly and cause catastrophe if actions such as travel restrictions are not taken at right time. Du et al. (2020) calculated the probability of transportation of COVID-19 from Wuhan to 369 other cities in China as it was already late before China quarantined Wuhan on January 23, 2020, to contain the virus. They found risk of COVID-19 development in few cities within China with greater than 99\% risk before placing the Wuhan travel restrictions. In another study of COVID-19 outbreak, modeling assessment of the effects of travel limitations Chinazzi et al. (2020) found that additional travel restrictions such as 90 percent limitations, will make at least few weeks delays on case surge if put together with public health interventions and behavioral changes in order to reduce disease transmissibility.

In another study of travel restriction's impact on COVID-19 cases Anzai et al. (2020) explicitly computed the impact of restricted travel volume to and from China on the spread of COVID-19 out of China. Although they find the number of delays for a major epidemic occurrence was only 2 days because of travel restriction from China, however, the reduction of case number was high along with the reduction of probability of a major epidemic. Although the studies, cited above, have contributed to the literature of travel restrictions they could not confirm the effect of travel restrictions on the number of deaths from COVID-19 since their papers were too early to measure that effect because of unavailability of data which is now existing. In this paper, we have endeavored to model the effect of global travel restrictions on the number of deaths from COVID19 by utilizing data from various sources, and our findings represent the whole world.

\section{The Trade-off Between Human Lives and Economic Stability}

There are also critical issues related with implementing strong global travel restriction with its economic outcome for countries. Perhaps a complete lockdown of a country from outside world in the free-commerce world might have many economic and social ramifications. Besides, the policy makers and government bodies face the complex decision of making trade-offs of mitigating loss of lives of people and maintaining emergency medical supply across world and surviving their economies and businesses. Devi (2020) described the negative consequences of travel restrictions on the movement of vital equipment and personnel for treating COVID-19 patients as countries are restricting travel to stem the pandemic.

Besides, there is fear that COVID-19 can accelerate and widen the existing economic inequality and inadequate social protections for lower social class worldwide (Berger, Evans, Phelan, \& Silverman, 2020). During a global pandemic along with economic and social uncertainty poor people suffer more whereas rich people get an increase in their combined wealth at the peak time of unemployment, poverty, and debt (Paremoer, Nandi, Serag, \& Baum, 2021).

Countries across the world had to budget aid package for tackling the wound posed by the virus in people's lives, small business, and other sectors of economy. For instance, on the 27th of March 2020 the U.S government offered a \$2 trillion 'virus-aid package' to support the economy (Mascaro, 2020). The bill offered support to millions of US workers, small businesses, aviation, 
healthcare and local governments (Aljazeera, 2020). This side of negative consequences of global travel restrictions along with internal lockdown in countries on supply of resources, personnel livelihood and overall stability of economies are beyond our analysis as we do not come up with data on that part.

\section{Data Section}

Our initial sample size includes 221 countries which includes 195 United Nations (UN) member countries and some dependent territories for which independent data are available. Some of the countries included in the analysis are dependent territories under some independent countries such as The United Kingdom, which has 14 overseas territories under its jurisdiction. Though they are not independent countries but most of them are internally self-governing with the UK keeping responsibility for protection and foreign affairs. However, we have excluded two countries as the data were missing for many variables for these two territories. The two omitted countries are MS Zaandam and Diamond Princess. So, the final sample size includes 219 countries and territories for which we collected data on COVID-19 as well as their geographic and demographic aspects. More details of the variables included are provided in the table 1. A list of all countries included in the analysis is provided in the appendix. All data from all sources including Wikipedia, World population review and Worldometer are collected during the period of Feb 1, 2021, to Feb 07, 2021.

Table 1 Descriptions of variables in the study

Variable Definition

Deaths_1M_pop (CDETH) Covid-19 deaths in countries in per million population

Total_Cases_1M_pop

(CASE)

Tests_1M_pop (TEST)

Population_ML (POP)

Avg_yr_temp_61_90_Celsius

(TEM)

AlcoholPerDay_GRM

(ALCH)

Travel_Restrictions_Status

(TRS)
Covid-19 cases in countries in per million population

Covid-19 test done in per million population

Population of countries in million

Average temperature of 1961-1990 of the countries in the study

Average per day alcohol consumption in gram by people

3-level categorical variable of global, selective or no travel

restrictions 
The first four variables from table 1: Deaths_1M_pop, Total_Cases_1M_pop, Tests_1M_pop, Population_ML are collected from Worldometer.info. The Avg_yr_temp_61_90_Celsius, Travel_Restrictions_Status data are collected form Wikipedia.com. The data on Alcohol_Per_Day_GRM is collected from Worldpopulationreview.com. Most of the data sources are open accessible and so can be retrieved by anyone.

\section{Methods}

Our regression equation estimation is as follows. We have placed number of deaths from covid19 (CDETH) as a function of total case in million (CASE), test in million (TEST), population in million (POP), average temperature from 1961-1990 for countries (TEM), average alcohol consumption per day in gram (ALCH), and the level of travel restriction they took (TRS) and error term (e) which incorporate unobservable in the model specification.

$$
\mathrm{CDEATH}=\beta_{0}+\beta_{1} \mathrm{CASE}+\beta_{2} \mathrm{TEST}+\beta_{3} \mathrm{POP}+\beta_{4} \mathrm{TEM}+\beta_{5} \mathrm{ALCH}+\beta_{6} \mathrm{TRS}+\mathrm{e}
$$

We have used ordinary least square (OLS) estimation method in calculating equation 1 above and our coefficients. OLS is supposed to be best linear unbiased estimator (BLUE) with cross sectional data when six Gauss Markov assumptions are met. Once the six Gauss Markov OLS assumptions - 1) linear in parameter; 2) independent sample; 3) error follow normal distribution, that is; 4) mean zero, and 5) variance is sigma square $\left(\sigma^{2}\right)$; and 6) variation in all independent variables that means none of independent variable is constant are met, then OLS is best estimator for cross sectional data (Wooldridge, 2013, pp. 45-158). In this case we assume that the data we analyzed here fulfill all six assumptions and the error (e) follow normal distributions.

Table 2 Key summary statistics of the variables in the study

\begin{tabular}{lccccc}
\hline & mean & std.dev & median & min & $\max$ \\
\hline \hline Deaths_1M_pop & 373.30 & 478.90 & 121.00 & 0.20 & 2286.00 \\
Total_Cases_1M_pop & 20060.10 & 24689.20 & 9687.00 & 3.00 & 128488.00 \\
Tests_1M_pop & 381631.30 & 649373.80 & 165023.00 & 576.00 & 4690010.00 \\
Population_ML & 35.60 & 140.20 & 6.60 & 0.00 & 1439.30 \\
Avg_yr_temp_61_90_Celsius & 18.68 & 8.07 & 21.80 & 0.70 & 28.29 \\
AlcoholPerDay_GRM & 34.11 & 15.12 & 33.40 & 2.10 & 79.10 \\
Travel_Restrictions_Status & 2.15 & 0.86 & 2.00 & 1.00 & 3.00 \\
\hline
\end{tabular}


All correlations among variables in the study are given in table 3 . The sign of correlations, which is referred to as model free results, are almost expected to our hypothesis. The correlation of Deaths_1M_pop and Total_Cases_1M_pop is a little high as we assume to be as these two are very closely connected. High correlation between these two variables assumably arising from the that fact that more cases lead to more deaths from COVID-19. For instance, U.S is unfortunately leading the number of cases along with the number of deaths from Covid-19 in comparison to other countries in the world, especially in comparison to other comparable developed countries (Health, 2021). Other than that, we do not see any high correlations among the included variables i.e., multicollinearity is not present among the variables.

Table 3 Correlation matrix of variables in the study

\begin{tabular}{|c|c|c|c|c|c|c|c|c|}
\hline & & 1 & 2 & 3 & 4 & 5 & 6 & 7 \\
\hline 1 & Deaths_1M_pop & 1.00 & & & & & & \\
\hline 2 & Total_Cases_1M_pop & 0.81 & 1.00 & & & & & \\
\hline 3 & Tests_1M_pop & 0.22 & 0.49 & 1.00 & & & & \\
\hline 4 & Population_ML & -0.07 & -0.11 & -0.08 & 1.00 & & & \\
\hline 5 & Avg_yr_temp_61_90_Celsius & -0.43 & -0.41 & -0.26 & -0.03 & 1.00 & & \\
\hline 6 & AlcoholPerDay_GRM & 0.07 & 0.07 & -0.03 & -0.01 & -0.15 & 1.00 & \\
\hline 7 & Travel_Restrictions_Status & 0.07 & 0.02 & -0.09 & -0.11 & 0.16 & 0.31 & 1.00 \\
\hline
\end{tabular}

\section{Results}

We have run three different models, all of which follow ordinary least square methods, the results of which are provided in table 4 . The F statistics are significant for all three Models. The overall model fit scores, which is shown by adjusted $\mathrm{R}^{2}$, for all three models are respectively $.69, .74$ and .72. our main focus is on model three with our variable of interest: travel_restrictions_status. Although model three shows slightly lower model fit score than model 2, however, the model is overall significant as F statistics show the significance at $p<0.01$.

Table 4 Results of Ordinary Least Square

Regressions 


\begin{tabular}{|c|c|c|c|}
\hline \multirow[b]{2}{*}{ Independent variable } & \multicolumn{3}{|c|}{ Dependent variable: Deaths_1M_pop } \\
\hline & Model 1 & Model 2 & Model 3 \\
\hline \multirow[t]{2}{*}{ Total_Cases_1M_pop } & $0.017 * * *$ & $0.018 * * *$ & $0.018 * * *$ \\
\hline & $(0.001)$ & $(0.001)$ & $(0.001)$ \\
\hline \multirow[t]{2}{*}{ Tests_1M_pop } & $-0.0001 * * *$ & $-0.0003 * * *$ & $-0.0003 * * *$ \\
\hline & $(0.000)$ & $(0.000)$ & $(0.000)$ \\
\hline \multirow[t]{2}{*}{ Population_ML } & 0.07 & -0.01 & -0.033 \\
\hline & $(0.130)$ & $(0.120)$ & $(0.130)$ \\
\hline \multirow[t]{2}{*}{ Avg_yr_temp_61_90_Celsius } & & $-9.200 * * *$ & -5.000 \\
\hline & & $(2.800)$ & $(3.500)$ \\
\hline \multirow[t]{2}{*}{ AlcoholPerDay_GRM } & & & -0.72 \\
\hline & & & $(1.600)$ \\
\hline \multirow[t]{2}{*}{ Travel_Restrictions_Status2 } & & & $233.000 * * *$ \\
\hline & & & $(74.000)$ \\
\hline \multirow[t]{2}{*}{ Travel_Restrictions_Status3 } & & & 88 \\
\hline & & & $(59.000)$ \\
\hline \multirow[t]{2}{*}{ Constant } & 38 & $270.000 * * *$ & 141 \\
\hline & $(28.000)$ & $(69.000)$ & $(103.000)$ \\
\hline Observations & 189 & 156 & 125 \\
\hline $\mathrm{R} 2$ & 0.7 & 0.75 & 0.74 \\
\hline \multirow[t]{2}{*}{ Adjusted R2 } & 0.69 & 0.74 & 0.72 \\
\hline & $142.000 * * *(\mathrm{df}=$ & $112.000 * * *(\mathrm{df}$ & $47.000 * * *(\mathrm{df}$ \\
\hline F Statistic & $3 ; 185)$ & $=4 ; 151)$ & $=7 ; 117)$ \\
\hline
\end{tabular}


Note: ${ }^{*} p * p * * * p<0.01$ represent significance at 10,5 and 1 percent level respectively

Standard errors are in parentheses. *Significance is based on two tailed tests

In model 1, we have included a few control variables for this analysis which are Total_Cases_1M_pop, Tests_1M_pop, Population_ML. We see the coefficients are according to our expectations. Total_cases_1M is positively affecting the Deaths_1M_pop. The sign of the coefficient is similar to the correlation sign of the two variables. Similarly, it is recognizable from the covid-19 data that the countries with high COVID-19 case see more deaths form COVID-19. Moreover, we can observe from the World Health Organization's (WHO) weekly update on 02 February 2021, there is a $13 \%$ decline in new cases as compared to the previous week, which leads new deaths to a $1 \%$ decline as compared to the previous week (Organization, 2021). Therefore, the number of cases and the number of deaths from COVID-19 are positively correlated, and it is expected. Although the correlation shows positive association between Tests_1M_pop and COVID-19 death, the causal relation is describing that more tests of COVID-19 lead to a reduced number of deaths from COVID-19. It makes sense to infer from our results that when people get tested, they know their COVID-19 status and can take proper actions if they are infected. Subsequently, they can take actions to their COVID-19 recovery which in turn reduce the total number of deaths. We included population_ML as demographic control variable so that it does control any biasedness of our main findings arriving from high variance of most populated countries in the world. The population variable is showing a positive connection with the number of deaths from COVID-19 as per our anticipation. 


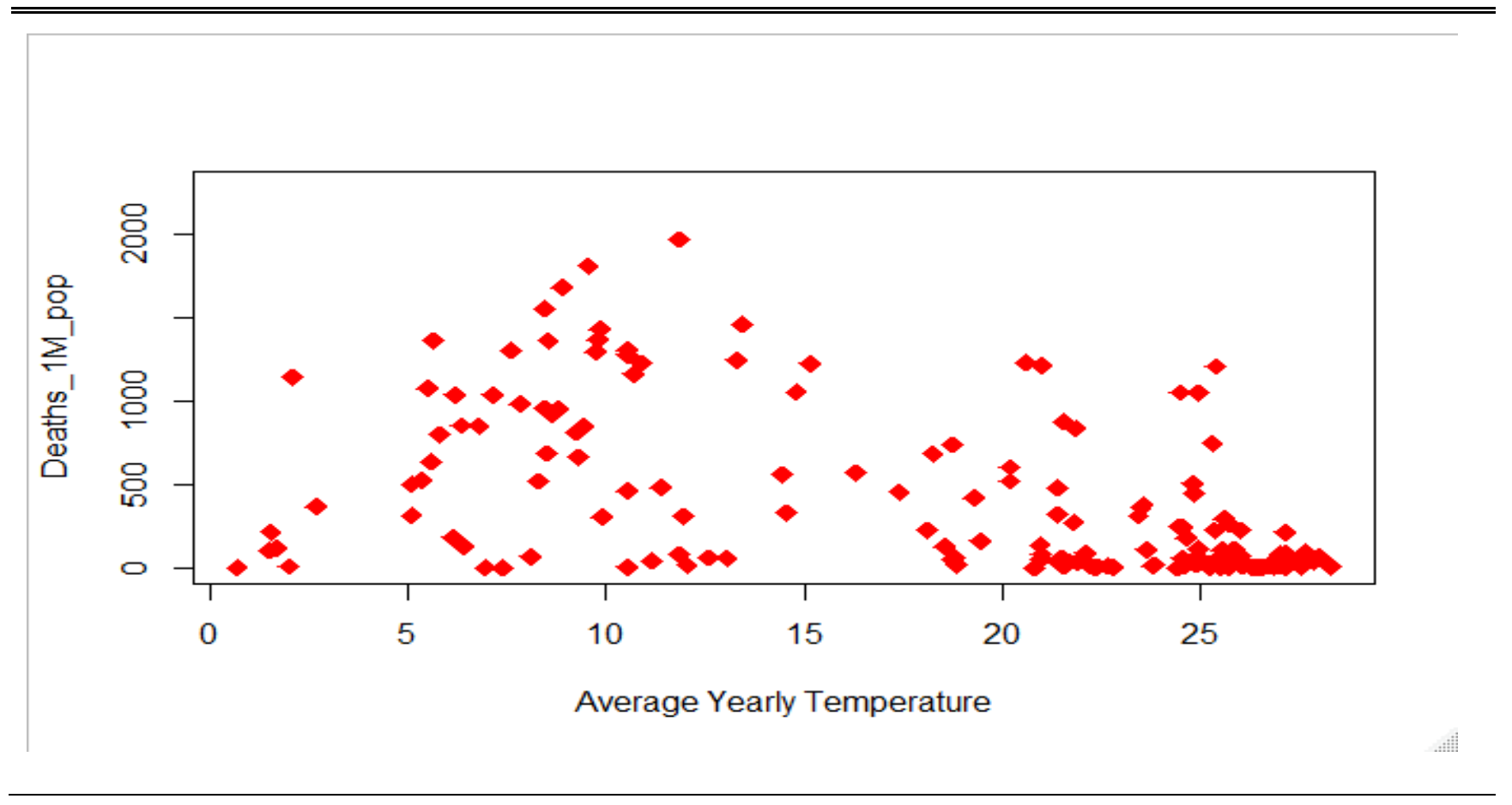

Fig. 1 Average Yearly Temperature and Number of Deaths from COVID-19

We have as well controlled for the average yearly temperature (Celsius) for all countries in the study in model 2 and model 3 . There might be low temperature effect on the dependent variable, deaths in million, as countries have variations in average yearly temperature. Since it is very common notion that corona virus can survive and spread quickly in cold temperature just as other respiratory illnesses do. According to Dangerfield (2020) decline in temperature has led to a spike in the number of cases of COVID-19 throughout Canada. According to same news report, Canadian Prime Minister, Justin Trudeau, expressed concern that as cold winter entered in season the country was expecting another wave of COVID-19 case. According to our supposition, the higher the temperature the lower the number of deaths from COVID-19 has prevailed. We see both in model 3 and model 4 that the coefficient of average yearly temperature is negative though it is significant in model 2 but not in model 3. We have depicted the association between average yearly temperature and the number of deaths from COVID-19 in figure 1 which indicates that warm temperature contributes to the reduced number of deaths from COVID-19. This might be the reasoning that countries such as United States (U.S.) which has low average temperature (12.42 degrees Celsius in 2020) is leading in both COVID-19 cases and deaths in the world. Yet again, this association might be moderated by the total number of populations in individual countries. For example, Canada is usually much colder in average temperature than U.S because of its northern position in world map but the number of populations is around one eleventh of U.S. Therefore, usually we can expect a lower number of cases and deaths in Canada than U.S. That is evident from our population variable's coefficients too. 
We have included average alcohol consumption per day in gram as we know any drink is usually consumed in cold temperature along with cold ice. Thus, we wanted to see whether an increased average alcohol consumption per day can lead to higher number of deaths from COVID-19. This is the only exception which did not show significant result, and the sign is not according to our supposition. The reason might be because of the fact that contrary to our common assumption some Middle Eastern and Asian countries' people drink much more than some developed and western countries. However, the alcohol intake per day shows a negative correlation with the number of deaths from COVID-19 worldwide.

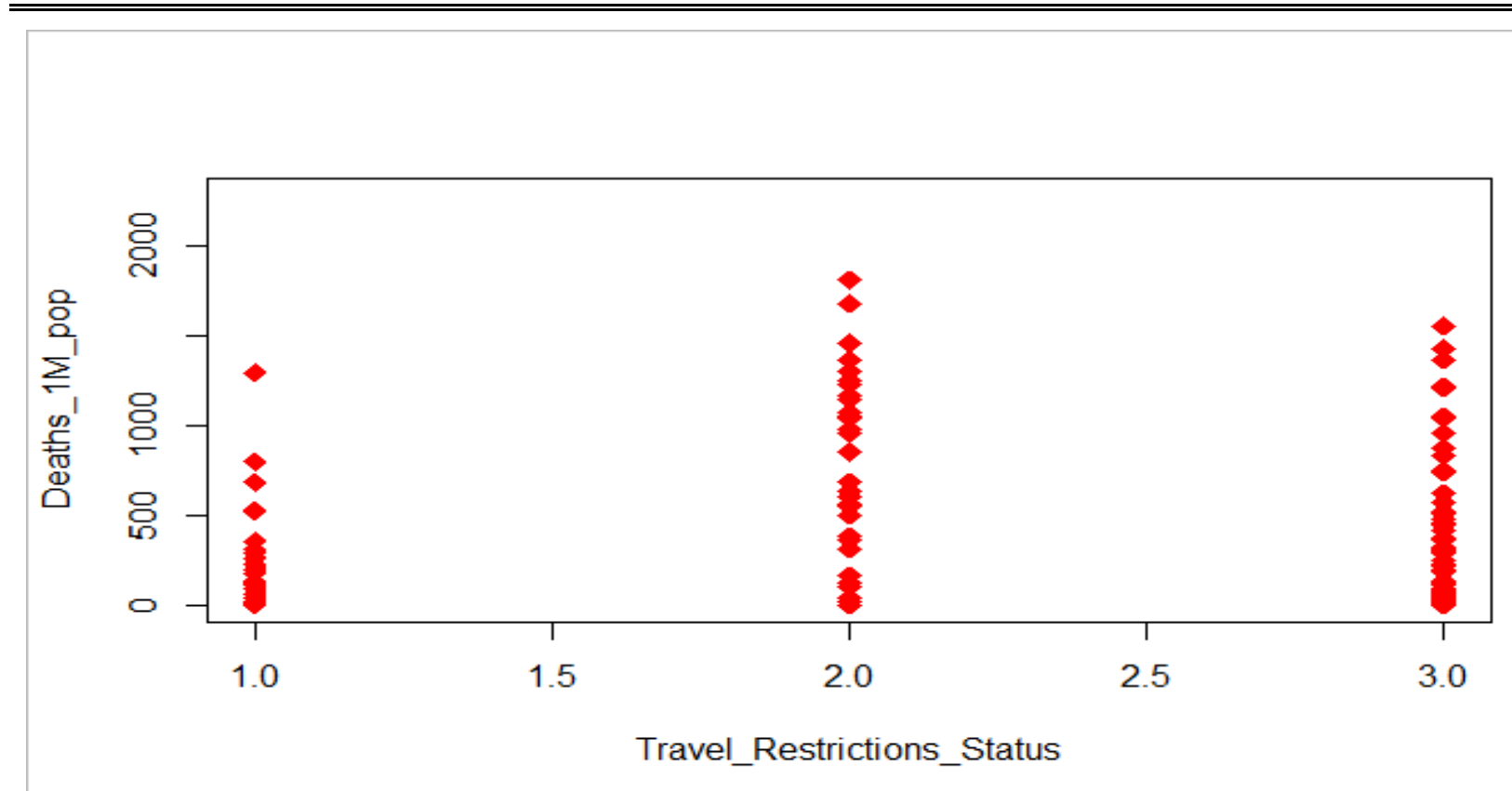

Fig. 2 Travel Restrictions Status and Number of Deaths from COVID-19.

Our main interest remains in the model 3, on the coefficient of travel_restriction_status. The F statistics of this model is highly statistically significant at $p<0.01$. We have incorporated this travel_restriction_status variable as three-level categorical variable- 1) global travel restrictions; 2) selective i.e., country specific travel restrictions; and 3) no global travel restrictions. They are coded respectively as 1, 2, and 3 in the analysis. The base category of global travel restrictions, which is set in intercept, shows a positive causation with number of deaths from COVID-19. That is rational since we probably do not expect that travel restrictions can reduce the number of deaths 
from to zero from a global pandemic. However, our interest was to see whether the countries which did not imply global travel restrictions at the time of high spike of the virus leads to more deaths from COVID-19. Expectedly, the second category of global travel restrictions variable shows a significantly positive effect towards more death from COVID-19 for countries which implemented limited global travel restrictions i.e., restrictions for specific countries. The coefficient is 233 points higher than base category of global travel restriction with $p<0.01$. That means in selective global travel restrictions state on average 233 more people per million will die than complete travel restrictions condition. The level differences of different status of global_travel_restrictions on the number of deaths from COVID-19 have been shown in figure 2. Although, the last category of our variable of interest, global_travel_restrictions, no_global_restriction is not significant, however, the coefficient is positive according to our anticipation. Thus, our findings are not deviated from what we hypothesized that global_travel_restrictions can lead to reduced spread and reduce number of deaths from the virus. Our finding on travel restrictions impact on the number of deaths from COVID-19 is similar to the findings from previous research (Linka, Peirlinck, Sahli Costabal, $\&$ Kuhl, 2020) which also looked at the travel restrictions impact on COVID-19 case importations across European countries. We have also noticed distinctions in terms of number of cases and deaths from COVID-19 in The United States where all states did not take measures such as travel restrictions or lockdown at same level or magnitude (Studdert, Hall, \& Mello, 2020). Besides, COVID-19 transmission model Wuhan, China shows that the authority was already weeks late in implementing lockdown and travel restrictions before the spread of COVID-19 across China (Chinazzi et al., 2020).

\section{Limitations}

Previous research on travel restrictions effect on COVID-19 case include the low transmissibility measures such as rate of mask wearing which they defined as behavior or regulatory issues; closing 
places which have high probability of virus spread such as bar, restaurant, night club; taking proper preventive behavioral measures such as maintaining six fit distances, avoiding crowdy places to reduce spread play vital role when coincide with travel restrictions (Chinazzi et al., 2020; Du et al., 2020). Controlling the low transmissibility measures in the model specification would make our model results more cogent. Besides, it would be better if we could also show country specific assessment on whether low transmissibility measures play a role in interaction with travel restrictions to reduce number of cases from COVID-19.

\section{Robustness Check}

To check the validity and robustness of our main findings, we run the same models in table 4 with external data on the number of cases and deaths from COVID-19 from CNN COVID-19 worldwide tracker site: World Covid-19 tracker: Latest cases and deaths by country (cnn.com) keeping all other control variables (which are sourced from same sites for main study as mentioned in table 1) same. After that, we found the analogous results as we found with our main analysis. Consequently, the findings we got in this analysis stand fair enough to make its conclusion. The results of robustness check analysis are provided in table 5.

Table 5 Results of Ordinary Least Square regressions with CNN data for robustness check

Dependent variable: Deaths_1M_pop

\begin{tabular}{lccc}
\hline & Model-1 & Model-2 & Model-3 \\
\hline \hline Total_Cases_1M_pop & $0.017^{* * * *}$ & $0.018^{* * * *}$ & $0.018^{* * * *}$ \\
& $(0.001)$ & $(0.001)$ & $(0.001)$ \\
Tests_1M_pop & $-0.00001^{* *}$ & $-0.00003^{* * *}$ & $-0.00003^{* * * *}$ \\
& 0.000 & $(0.000)$ & $(0.000)$ \\
Population_ML & 0.008 & -0.001 & -0.004 \\
& $(0.013)$ & $(0.013)$ & $(0.013)$ \\
Avg_yr_temp_61_90_Celsius & & $-1.100^{* * * *}$ & -0.550 \\
& & $(0.290)$ & $(0.350)$ \\
AlcoholPerDay_GRM & & & -0.064
\end{tabular}

Travel_Restrictions_Status2

$26.000^{* * * *}$ 


\begin{tabular}{lccc}
\hline Observations & 198 & 162 & 129 \\
$\mathrm{R}^{2}$ & 0.7 & 0.75 & 0.75 \\
Adjusted $\mathrm{R}^{2}$ & 0.69 & 0.75 & 0.73 \\
& $28.000(\mathrm{df}=$ & $26.000(\mathrm{df}=$ & $26.000(\mathrm{df}=$ \\
Residual Std. Error & $194)$ & $157)$ & $121)$ \\
& $151.000^{* * *}(\mathrm{df}=$ & $120.000^{* * *}(\mathrm{df}$ & $51.000^{* * *}(\mathrm{df}=$ \\
F Statistic & $3 ; 194)$ & $=4 ; 157)$ & $7 ; 121)$ \\
& & &
\end{tabular}

Note: ${ }^{*} \mathrm{p} * \mathrm{p}^{* * *} \mathrm{p}<0.01$ represent significance at 10,5 and 1 percent level respectively

\section{Conclusion}

It is well accepted now that COVID-19 has created disruptions at all level of lives, economies, business, and countries (Maria et al., 2020). When the first spike was getting accelerated at the time of February and March in 2020, all governments did not give equal importance to get the spread of the virus under check. We can see it from our global travel restrictions variable's three levels: 1) global travel restrictions; 2) selected restriction i.e., for selected countries only; and 3) no global restrictions. Our findings reinforce our hypothesis that the lack of global travel restrictions at the time of spike of COVID-19 have led to the increased number of deaths worldwide. We believe that the global travel restrictions if implemented properly at the beginning of COVID-19 spike by those noncomplying countries could be sufficient to reduce the number of cases and deaths across countries. Our analysis provides empirical evidence and contributes to the concept that global travel restrictions lead to reduced number of deaths from COVID-19. The findings from this paper can be taken into account in future for any further spike of COVID-19 along with any other pandemic in future.

Since this is a cross country analysis, we could not include analysis of individual country's scenario based on its global travel restrictions. We expect some future research will take initiative to determine the effect of global travel restrictions at individual country level. We also observed that some countries such as U.S. recommended their residents to reduce their domestic travel. 
Therefore, future research can also look at the effect of domestic travel restrictions on the number of cases and deaths from COVID-19 at specific country level.

\section{List of abbreviations}

COVID-19: Coronavirus Disease 2019

SARS-CoV-2: severe acute respiratory syndrome COVID-19

CDC: Center for Disease Control and Prevention

U.S.: United States

UK: United Kingdom

OLS: Ordinary Lease Square

\section{Declarations}

Ethics approval and consent to participate

Not applicable

\section{Consent for publication}

Not applicable

\section{Availability of data and materials}

The datasets used and/or analyzed during the current study are available from the corresponding author on reasonable request.

\section{Declaration of Conflicting Interests}

The author declared no potential conflicts of interest with respect to the research, authorship, and/or publication of this article. 


\section{Funding}

The author received no financial support for the research, authorship, and/or publication of this article.

\section{Author's contributions}

All the works related to the manuscript including writing the manuscript, collecting data, and analyzing data are done by the author himself. All remaining errors are the sole responsibility of the author.

\section{Acknowledgements}

I would like to thank all my mentors who taught me the fundamentals of conducting research in social science. They have contributed by straightening my confusions related to methods in research in general, and mostly giving me encouragement in my research endeavors and enthusiasm.

\section{References}

Aljazeera. (2020). Who gets what from the $\$ 2$ trillion US virus aid package. Retrieved from https://www.aljazeera.com/economy/2020/3/26/who-gets-what-from-the-2-trillion-usvirus-aid-package

Anzai, A., Kobayashi, T., Linton, N. M., Kinoshita, R., Hayashi, K., Suzuki, A., . . . Akhmetzhanov, A. R. (2020). Assessing the impact of reduced travel on exportation dynamics of novel coronavirus infection (COVID-19). Journal of clinical medicine, 9(2), 601.

Bank, T. W. (2021). Global Economy to Expand by 4\% in 2021; Vaccine Deployment and Investment Key to Sustaining the Recovery. Retrieved from https://www.worldbank.org/en/news/press-release/2021/01/05/global-economy-toexpand-by-4-percent-in-2021-vaccine-deployment-and-investment-key-to-sustaining-therecovery

Berger, Z. D., Evans, N. G., Phelan, A. L., \& Silverman, R. D. (2020). Covid-19: control measures must be equitable and inclusive. In: British Medical Journal Publishing Group.

Chinazzi, M., Davis, J. T., Ajelli, M., Gioannini, C., Litvinova, M., Merler, S., . . Sun, K. (2020). The effect of travel restrictions on the spread of the 2019 novel coronavirus (COVID-19) outbreak. $\quad$ Science, 368(6489), 395-400. Retrieved from https://www.ncbi.nlm.nih.gov/pmc/articles/PMC7164386/pdf/368_395.pdf Retrieved from https://www.ncbi.nlm.nih.gov/pmc/articles/PMC7164386/pdf/368_395.pdf

COVID, T. I., Reiner, R., Barber, R., \& Collins, J. (2020). Modeling COVID-19 scenarios for the United States. Nature medicine.

Dangerfield, K. (2020). Winter in a pandemic: How cold air could make the coronavirus spread more easily. globalnews.ca. Retrieved from https://globalnews.ca/news/7355406/winterpandemic-cold-air-coronavirus/ 
Devi, S. (2020). Travel restrictions hampering COVID-19 response. The Lancet, 395(10233), 1331-1332. https://www.ncbi.nlm.nih.gov/pmc/articles/PMC7180010/pdf/main.pdf Retrieved from https://www.ncbi.nlm.nih.gov/pmc/articles/PMC7180010/pdf/main.pdf

Du, Z., Wang, L., Cauchemez, S., Xu, X., Wang, X., Cowling, B. J., \& Meyers, L. A. (2020). Risk for transportation of coronavirus disease from Wuhan to other cities in China. Emerging infectious diseases, 26(5), $1049 . \quad$ Retrieved from https://www.ncbi.nlm.nih.gov/pmc/articles/PMC7181905/pdf/20-0146.pdf Retrieved from https://www.ncbi.nlm.nih.gov/pmc/articles/PMC7181905/pdf/20-0146.pdf

Health, C. (2021). Tracking coronavirus' global spread. Retrieved from https://www.cnn.com/interactive/2020/health/coronavirus-maps-and-cases/

Linka, K., Peirlinck, M., Sahli Costabal, F., \& Kuhl, E. (2020). Outbreak dynamics of COVID-19 in Europe and the effect of travel restrictions. Computer Methods in Biomechanics and Biomedical Engineering, 23(11), 710-717. Retrieved from https://www.tandfonline.com/doi/pdf/10.1080/10255842.2020.1759560?needAccess=true Retrieved from https://www.tandfonline.com/doi/pdf/10.1080/10255842.2020.1759560?needAccess=true

Maria, N., Zaid, A., Catrin, S., Ahmed, K., Ahmed, A.-J., Christos, I., . . Riaz, A. (2020). The socio-economic implications of the coronavirus pandemic (COVID-19): A review. International Journal of Surgery, 78, 185-193.

Mascaro, A. T. A. L. (2020). Coronavirus: U.S. Senate passes $\$ 2.2$. trillion aid package in response to COVID-19. Retrieved from https://globalnews.ca/news/6734283/coronavirus-senateaid-trillion-us-package/

Organization, W. H. (2020a). https://www.who.int/director-general/speeches/detail/who-directorgeneral-s-statement-on-ihr-emergency-committee-on-novel-coronavirus-(2019-ncov) [Press release]. Retrieved from https://www.who.int/director-general/speeches/detail/whodirector-general-s-statement-on-ihr-emergency-committee-on-novel-coronavirus-(2019ncov)

Organization, W. H. (2020b). Novel Coronavirus ( 2019-nCoV): situation report, 3.

Organization, W. H. (2021, 02/02/2021). COVID-19 Weekly Epidemiological Update. Retrieved from https://www.who.int/publications/m/item/weekly-epidemiological-update---2february-2021

Paremoer, L., Nandi, S., Serag, H., \& Baum, F. (2021). Covid-19 pandemic and the social determinants of health. bmj, 372 .

Prevention, C. f. D. C. a. (2021). Holiday Tips. Retrieved from https://www.cdc.gov/coronavirus/2019-ncov/daily-life-coping/holidays/winter.html

Sahu, K., Mishra, A., \& Lal, A. (2020). Coronavirus disease-2019: An update on third coronavirus outbreak of 21st century. QJM: An International Journal of Medicine, 113(5), 384-386. Retrieved

from https://www.ncbi.nlm.nih.gov/pmc/articles/PMC7107240/pdf/hcaa081.pdf Retrieved from https://www.ncbi.nlm.nih.gov/pmc/articles/PMC7107240/pdf/hcaa081.pdf 
Sharma, S. V., Chuang, R.-J., Rushing, M., Naylor, B., Ranjit, N., Pomeroy, M., \& Markham, C. (2020). Peer Reviewed: Social Determinants of Health-Related Needs During COVID-19 Among Low-Income Households With Children. Preventing chronic disease, 17.

Studdert, D. M., Hall, M. A., \& Mello, M. M. (2020). Partitioning the curve-Interstate travel restrictions during the COVID-19 pandemic. New England Journal of Medicine, 383(13), e83. https://www.nejm.org/doi/pdf/10.1056/NEJMp2024274?articleTools=true Retrieved from https://www.nejm.org/doi/pdf/10.1056/NEJMp2024274?articleTools=true

The bloomberg, c. (2021). The Path to Immunity Around the World. Retrieved from https://www.bloomberg.com/graphics/covid-vaccine-tracker-global-distribution/

Thompson, R. N. (2020). Novel coronavirus outbreak in Wuhan, China, 2020: intense surveillance is vital for preventing sustained transmission in new locations. Journal of clinical medicine, 9(2), 498.

University, C. f. S. S. a. E. C. a. J. H. (2021). Global Coronavirus Death update. Retrieved from https://coronavirus.jhu.edu/map.html

Wang, Z., Duan, Y., Jin, Y., \& Zheng, Z.-J. (2020). Coronavirus disease 2019 (COVID-19) pandemic: how countries should build more resilient health systems for preparedness and response. Global Health Journal, 4(4), 139-145. Retrieved from https://www.ncbi.nlm.nih.gov/pmc/articles/PMC7719199/pdf/main.pdf Retrieved from https://www.ncbi.nlm.nih.gov/pmc/articles/PMC7719199/pdf/main.pdf

Wooldridge, J. M. (2013). Introductory Econometrics: A modern Approach. Mason,OH: Cengage Learning.

Wu, J. T., Leung, K., \& Leung, G. M. (2020). Nowcasting and forecasting the potential domestic and international spread of the 2019-nCoV outbreak originating in Wuhan, China: a modelling study. The Lancet, 395(10225), 689-697. Retrieved from https://www.ncbi.nlm.nih.gov/pmc/articles/PMC7159271/pdf/main.pdf Retrieved from https://www.ncbi.nlm.nih.gov/pmc/articles/PMC7159271/pdf/main.pdf 